manufacturing and installation of fiber composites and adhesives for structural applications presented their latest technologies.

The field of Fiber Composites in Construction is evolving very quickly. This is perhaps one of the fastest growing areas within civil engineering. As a result, the organisers of this conference have planned The Second Conference of this series for January of 1998 to present the latest findings in this area. This conference will also include a short course for the researchers who are interested in getting involved in this field and for practicing engineers who would like to incorporate these materials and techniques in their designs.

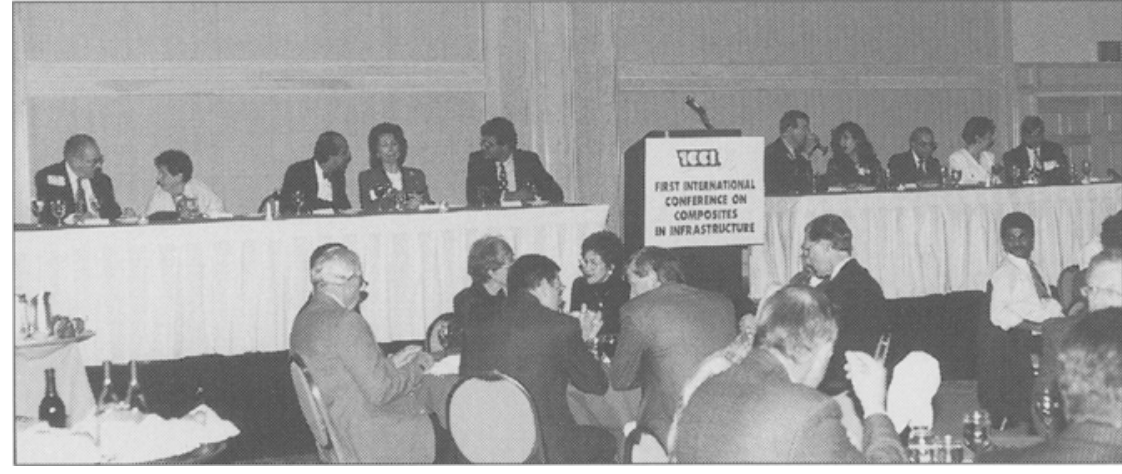

Banquet dinner.

The Second International Conference on Composites in Infrastructure, ICCl'98, will be held January 12-14, 1998, in Tucson,
Arizona, USA. The short course will precede the Conference on January 10 and $11,1998$.

\title{
7DBMC
}

\section{The 7th International Conference on the Durability of Building Materials and Components}

\author{
Stockholm, 19-23 May 1996
}

The 7th International Conference on the Durability of Building Materials and Components (7DBMC) was held in Stockholm, on May 19-23, 1996. The conference was a continuation of six previous events held respectively in Canada (1978), USA (1981), Finland (1984), Singapore (1987), UK (1990) and Japan (1993). The 8th DBMC conference will take place in Canada in 1999.

The area of durability and service life prediction of building materials and components has gradually become a scientific field of its own. Both from engineering and research have come strong reasons for the development of uniform methodologies for the assessment of the working life of building products. In the process to harmonise the wide-ranging interest in this field, this series of international conferences has played a decisive role by bridging different material and product areas and by giving researchers and practitioners an opportunity to meet every third year to discuss the latest R\&D achievements. Obviously, the connection to the work within the RILEM TCS 71-PSL, $100-$ TSL and the present 140-TSL has been, is and will be very strong, with many committee members deeply engaged, both scientifically and with the administration of the venues.

The 7th DBMC conference covered a number of themes ranging from theoretical aspects of service life prediction to the practical implementation in standards of knowledge about durability of building products. The themes were:

- Prediction methods and modelling

- Measurement and characterisation of degradation environment

- Service life data

- Field studies and evaluation methods

- Degradation mechanisms and materials characterisation - inorganic materials

- Degradation mechanisms and materials characterisation - organic materials

- Service life testing

- Standardisation and regulations

- Design for durability

- Maintenance planning and procedures. In addition, two workshops were held in connection with the conference sessions, namely: "Geographic information technology (GIT) for service life management of wooden constructions" and "Concrete durability in saline environment'.

The conference proceedings ( $E$ \& FN Spon, London, 1996) will, like those from the previous conferences, serve as a use- ful reference to all interested in the broad area of durability and service life prediction of building materials, components and construction.

\section{TC 124-SRC \\ Repair strategies for concrete structures dam- aged by steel corrosion}

No observations have been made on the "Draft recommendations for repair strategies for concrete structures damaged by reinforcement corrosion", published in Materials and Structures, 27 (171) (1994) 415-436.

Therefore, it would appear that no modifications are required and that this recommendation can be considered as final. 